\title{
ELECTRONIC DEMOCRACY - A WHITE BOOK OF STATE POLICY
}

\section{Abstract}

This article explores e-government systems, in particular e-democracy, gives a definition of the concept, considers the types of e-democracy, the goals of this system, the risks of implementation and imperfections in the current development environment of the digital economy. The level of development of information and communication technologies and the dependence of e-democracy on these technologies are also investigated.

Keywords: e-government, e-democracy, information and communications technology, goal, risks, strategy, digital economy, digital technology, administrative staff.

\section{References}

1. Vershinin M.S. Politicheskaya kommunikaciya v informacionnom obshchestve. Spb.: Izd-vo Mihajlova V.A., 2001. P. 90-91.

2. Kravchenko V.I. Politicheskaya kul'tura kak otrazhenie politiko-kommunikativnoj real'nosti obshchestva / Sbornik nauchnyh trudov "Aktual'nye problemy teorii kommunikacii". SPb.: Izd-vo SPbGPU, 2004. P. 59 - 71.

3. Lavrik N.V. Elektronnaya demokratiya: mirovoj opyt // Vestn. Zabajkal. gos. un-ta. 2017. T. 23. № 2. P. 67 - 75.

4. Movsesyan A. Sovremennye tendencii stanovlenii informacionnogo obshchestva v mirovoj ekonomike i Rossii // Obshchestvo i ekonomika. 2001. № 6. P. 32 - 46.

5. Omelichkin O.V. Elektronnaya demokratiya: ponyatie, problemy // Vestnik KemGU. 2014. № 1(57). P. 86 - 89.

6. Peskov D.N. Internet v rossijskoj politike: utopiya i real'nost' // Polis. 2002. № 1. P. 31 - 65.

7. CHebotareva A.A. Mekhanizmy elektronnoj demokratii: vozmozhnosti i problemy ih realizacii v Rossijskoj Federacii// Pravovaya informatika. Vyp. 3. 2012. P. 49 - 54.

\section{ИННОВАЦИОННЫЕ ПРЕОБРАЗОВАНИЯ КАК ИМПЕРАТИВ РЕАЛИЗАЦИИ ПРОМЫШЛЕННОЙ ПОЛИТИКИ}

Овчаренко

Георгий

Васильевич

доктор экономических наук, профессор кафедры менеджмента,

Южно-Российский институт управления - филиал Российской академии

народного хозяйства и государственной службы при Президенте РФ

(344002, Россия, г. Ростов-на-Дону, ул. Пушкинская, 70/54).

E-mail:menedjment@uriu.ranepa.ru

\section{Ларкина}

Наталья

Георгиевна

Некрасова

Виктория

Витальевна

кандидат экономических наук, доцент кафедры «Маркетинг и коммуникации в бизнесе», Южный федеральный университет

(344006, Россия, г. Ростов-на-Дону, ул. Большая Садовая, 105/42).

E-mail: nat1-la@yandex.ru

кандидат экономических наук, зав. кафедрой менеджмента, доцент, Южно-Российский институт управления - филиал Российской академии народного хозяйства и государственной службы при Президенте РФ (344002, Россия, г. Ростов-на-Дону, ул. Пушкинская, 70/54).

E-mail: menedjment@uriu.ranepa.ru

\section{Аннотация}

В статье рассматриваются нравственно-этические аспекты инновационных преобразований в инновационной деятельности организаций. Обосновывается на практических ситуациях необходимость инновационной активности человека в его жизнедеятельности. Показана значимость инновационной культуры в создании социального равновесия в коллективе. Предложены модели стратегическиинновационной диверсификации в инновационном развитии общества. Определены возможности воспроизводства инновационного потенциала с учетом личной ответственности руководителей. Дана оценка ключевых факторов инновационных преобразований в контексте инновационного образования и инновационного мышления руководителей. Обозначены особенности инновационного управления знаниями.

Ключевые слова: нравственно-этические аспекты, инновационный климат, самосовершенствование личности, инновационное развитие, инновационная активность, инновационные знания, инновационный потенциал, обновление производства, инновационные ценности.

Нарушение равновесия в социально-экономической системе возникает вследствие низкого уровня морального сознания экономических субъектов в контексте ценностей, идеалов, норм и принципов поведения, эмоций, чувств, убеждений, переживаний, которые отражают жизненнопрактический и исторический опыт людей в форме индивидуальных и коллективных представлений, при этом выполняют функции механизма социальной преемственности при организации жизнедеятельности. 
Авторы отмечают, что понимание вышеизложенного - это логика нравственно-этических аспектов в современных экономических отношениях на всех уровнях: мега-, макро-, мезо- и микро-, что обуславливает компромисс между взаимодействующими экономическими субъектами.

Обозначенная особенность компромисса при любых взаимодействиях определяется на практике уровнями инновационной культуры, то есть осознанием всеми значимости этики, нравов, традиций и специфики национального развития переходящие из поколений исторически сложившиеся, что обуславливает гуманистическую направленность благосостояния для людей, а также удовлетворения в своей жизнедеятельности.

Подтверждением вышеизложенного является инновационное развитие 000 «КЗ "Ростсельмаш"» на основе создания ее руководителями не только инновационных знаний персонала, но и инновационного климата и культуры в коллективах, определяющих разработку и производство конкурентоспособных новационных моделей комбайнов для страны, так как хлеб - это сила и могущество государства.

Как показывает практика развития общества, значимость и влияние уровня образования на социальную активность личности определяют степень ее участия в общественной и политической жизни, а также гражданского поведения, что обуславливает самоподдерживающийся климат доверия в коллективе.

Понимание вышеизложенного обуславливается тем, что человек в своей жизнедеятельности ориентирован на будущее, приобретая все новые социальные навыки при взаимодействии в коллективе самореализуется и стремится к самосовершенствованию с пониманием норм нравственности и справедливости.

Не случайно в условиях кризиса экономики ужесточается конкуренция за привлечение человеческих знаний, как источник обновления производства во всех отраслях промышленности для реализации инновационного прорыва в развитии страны при четком и гибком государственном регулировании этих процессов в неообществе.

Однако авторы отмечают, что переход экономики на инновационный уровень развития возможен только при применении инновационных знаний людей во всех аспектах: техническом, технологическом, организационно-управленческом на основе научного подхода и инновационного мышления руководителей всех уровней управления с учетом их личной ответственности за результат точно в срок, но при инновационной активности и инвестиционной валентности всех регионов РФ. Так как статистика и анализ инновационной активности организаций не превышает $10 \%$ согласно данных Росстата, особенно плохо в отраслях сырьевого комплекса.

В связи с вышеизложенным необходимо отметить, что исторический опыт показывает единственный механизм таких изменений в инновационной активности - институт гражданского общества с духовной нравственностью, то есть государство должно ориентировать социальноэкономическую активность на реализацию инновационного развития экономики, но при условии создания условий для самоорганизации российского общества при поддержке и контроле государства и личной ответственности руководителей всех уровней управления во всех отраслях экономики [1].

В силу вышеизложенного с практической точки зрения умение руководителей организации применять стратегию дифференциации продуктовых моделей по принципу технологической взаимопригодности позволяет не только улучшить координацию взаимодействия подразделений, но и расширить технологические возможности в этапах инновационного процесса, реализуя инновационные организационные структуры, что и обуславливает конкурентоспособность организации в контексте синергетического использования научного потенциала всех работников, обуславливающего достижение инновационной цели. В этой связи авторы отмечают, что появляется инновационный вектор руководителей на приоритетность производственного этапа в инновационном процессе при разработке и создании новшеств, коммерциализация которых - это и есть инновационные товар или услуга с учетом специфики деятельности, но и риска и изменений конъюнктуры спроса.

Примером такого научного подхода в реализации этапов инновационного процесса является 000 «КЗ "Ростсельмаш"» руководители которого создают новые модели комбайнов на основе инновационных знаний персонала и собственных инновационных технологий, что и обеспечивает инновационный уровень развития в контексте 75\% спроса комбайнов регионами РФ, одновременно реализуя инновационные модели на экспорт в количестве $20 \%$ выпуска комбайнов ${ }^{1}$. При этом постоянно совершенствуется организационная структура управления производством на всех уровнях управления во всех подразделениях с учетом тенденции и практики развитых стран и специфики развития российской экономики для перехода на новый уровень развития с реализацией

\footnotetext{
1 Газета «Ростсельмашевец» от 20.02.2018.
} 
инновационной стратегии диверсификации, что определяет опережение конкурентов по расширению сегмента спроса.

Совокупность вышеуказанных принципов обуславливает не только новое содержание этапов технологии управления производством, но и гибкое применение совершенствованных организационных структур моделей инновационной деятельности, осуществляющих реализацию инновационных проектов точно в срок, что создает синергетический эффект в инновационном развитии организации с учетом мировых тенденций и кризисных ситуаций [2].

Усложнение производственных процессов, увеличение наукоемкости создаваемой продукции (услуги), неопределенность конъюнктуры обуславливает наличие у руководителей вйдения инновационной стратегии развития и гибкой тактики ее реализации, что обеспечит переход на инновационный уровень деятельности с социально-экологическим вектором для повышения качества жизни людей и достижения нравственной справедливости в неообществе в контексте инновационного цикла 5-го и 6-го технологических укладов.

В силу вышеизложенного авторы предлагают помнить предложения Президента РФ В.В. Путина, что «надо искать решения, которые позволили бы нам преодолеть складывающуюся одностороннюю технологическую зависимость, ...необходимо выстроить эффективный механизм обновления экономики ...с эффективным сельским хозяйством, ...нам нужно тщательно выбрать приоритеты и сохранить научный и производственный потенциал» [3].

Так в своих исследованиях А. Кьелл отмечает, чтобы добиться успеха в XXI веке, нужно научиться управлять бесконечной инновацией - это никогда не прекращающийся поиск путей создания новых ценностей для всех, кого, так или иначе, затрагивает деятельность компании.

Теоретически исследования ученых разных стран подтверждают, что на практике происходит циклическое развитие общества, обоснованное человеческим интеллектом, который в условиях инновационно-информационного общества является определяющим фактором воспроизводства национального инновационного потенциала и его необходимым элементом для перехода общества на новый уровень развития - неообество, что подтверждается исследованиями русского ученого В.И. Вернадского о том, что биосфера переходит в новое эволюционное состояние ноосферу, перерабатывается научной мыслью человечества [4]. Таков новый исторический путь развития России.

Подтверждение этому - инновационная деятельность руководителей 000 «КЗ "Ростсельмаш"», создавших социально-мотивированные условия творческой деятельности персонала при изготовлении мирового уровня моделей комбайнов с реализацией его совокупного интеллекта, обуславливающего не только ответственность каждой личности, но и мировой уровень качества комбайнов.

С практической точки зрения, все отрасли промышленности должны быть обновлены в контексте инновационно-технологических изменений, то есть переход к 6-му технологическому укладу на основе доверительного взаимодействия государства, науки, образования, производства и общества в целях осуществления революционных изменений во всех производственных процессах и на всех уровнях управления при конкретной ответственности каждого участника этих процессов за конкретный результат.

Анализ вышеизложенного показывает, что весь коллектив должен работать над инновационным совершенствованием деятельности организации для увеличения производительности труда, чтобы обеспечить инновационное развитие экономики и мирового уровня качества жизни людей.

Авторы считают, что только инновационное мышление руководителей-организаторов и интеллект персонала являются ключевым вектором гибкой инновационной деятельности организации, обладающим способностью генерировать новые особые знания в синергию инновационного творчества для достижения инновационной цели - становление новой модели экономики инновационной с социально-экологическим вектором.

В своих исследованиях С.Д. Валентей отмечает, что в современных условиях цикличность эволюции в обществе определяет «революцию в производственных силах не как просто очередной технологический прорыв, а интеграцию качественных изменений в экономических, социальнокультурных, технологических и др. сферах развития с ценностной ориентацией постепенно закрепляемых в генетическом коде и обществе» [5, с. 58] (рис. 1).

В силу вышеизложенного, необходимо отметить оригинальность понимания русским ученым Н.Д. Кондратьевым того, что в силу количественной ограниченности, так и в силу качественного несовершенства нашего знания мы всюду лишены возможности абсолютно точного прогноза; однако в различных областях действительности фактические возможности стратегического предвидения весьма различны, так как человек своей единой тройственной природой биопсихического духовного существа определяет и трехмерность всей совокупности под названием «общество». 


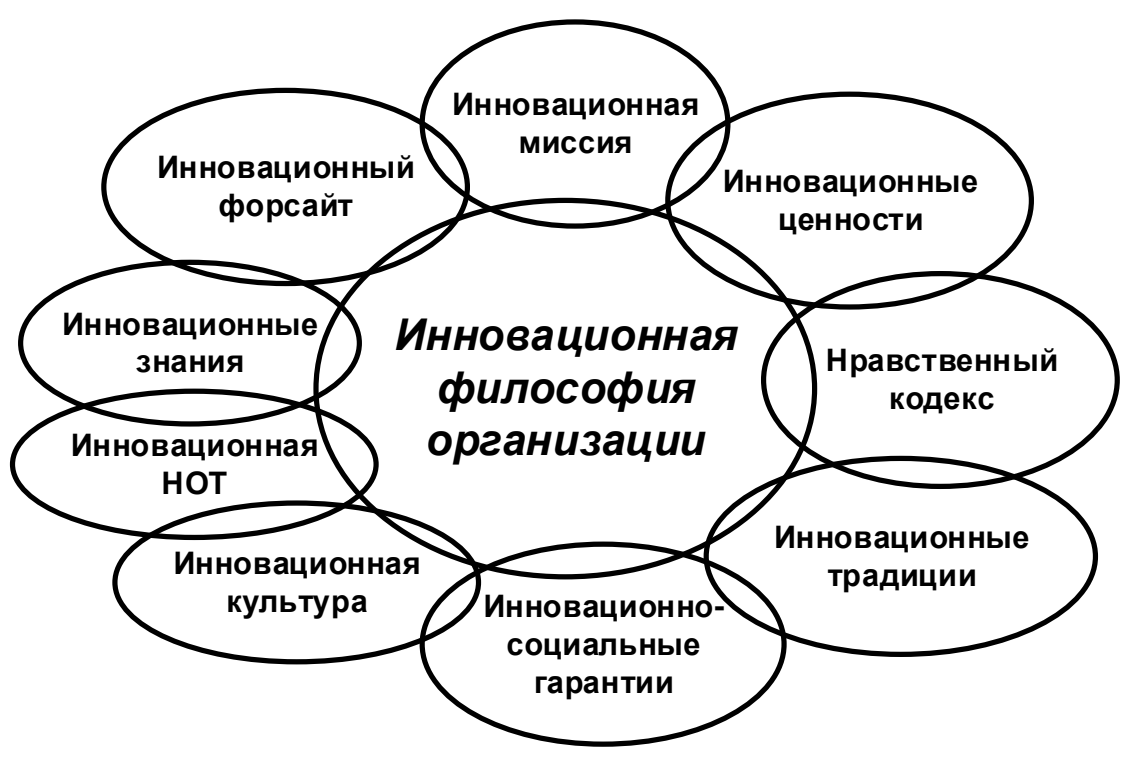

Рис. 1. Алгоритм инновационной гармонии

Авторы отмечают, что логика вышеизложенного обуславливает необходимость создания инновационно-социальной и ноосферной направленности становления новой экономики России это возрождение духовности - практический путь выхода из системного кризиса на основе творческого самовыражения каждого человека, то есть государство обеспечивает создание в обществе социального взаимодействия и восстановление в нем нравственно-социальной справедливости.

С теоретической точки зрения совершенно очевидна иннопарадигма становления новой философии созидания с пониманием руководителями приоритетности интеллекта человека: его знаний, квалификации и ценностей, то есть формируется НЕОмодель развития - инновационногуманная экономика для людей при инновационном переосмыслении моделей инновационного управления производством для занятости каждого работника на основе инновационного обучения креативности с учетом создания социо-экологических аспектов в новой экономике, чтобы стать интеллектуально-технологическим лидером с умением прогнозировать и оценивать будущий рост на современном этапе развития, а также понимать какие научные кадры будут нужны сейчас для становления инновационной экономики в регионах. Исходя из этого, необходимо создавать инновационных руководителей с инновационными компетенциями, способных создать инновационную инфраструктуру и формировать инновационную политику, определяющую инновационный прорыв в экономике.

С научной точки зрения инновационно-социальная и ноосферная направленность становления новой модели экономики России - это духовное возрождение и практический путь выхода из системного криза на основе творческого самовыражения каждого человека.

Так, В. Шепель в своих исследованиях отмечает, что «каждый руководитель организации призван в первую очередь произвести такую обязательную интеллектуальную акцию, как всестороннее теоретическое обоснование своей управленческой деятельности, ...он должен обладать фундаментальной и реальной для жизненного применения духовно-возвышенной компетенцией» [9].

В этот момент решающая радикальная роль государства - реализация инновационного управления интеллектуальным потенциалом страны и регионов с целью адаптации новой экономики к глобальному кризису при архи-гибком и быстром воспроизводстве, обновлении и создании инновационных знаний во всех отраслях промышленности и уровнях управления.

По мнению авторов, в практическом аспекте руководители компании 000 «КЗ"Ростсельмаш"» отвергли модель роста масштаба деятельности и определили переход к аспекту инновационного мышления в сторону изменяющихся приоритетов клиентов с учетом применения синергетической стратегии - диверсификации производства, то есть создали инновационную парадигму интенции. Тем самым реализовав свою инновационную политику с социально-экологической направленностью в инновационной деятельности на основе сформированной инновационной миссии и создании инновационного климата [6].

Однако авторы отмечают, что при наличии высокого экономического потенциала в каждом регионе наблюдаются низкие показатели уровня и качества жизни людей из-за неэффективного использования интеллектуального потенциала, что обуславливает государственное регулирование 
промышленности и инвестиций в регионах в целях роста благосостояния всех людей в регионах, но при условии использования методологии реализации приоритетных проектов при проведении структурной диверсификации.

В.В. Путин в 2016 г. отмечал, что мы рассматриваем машиностроение как один из драйверов отечественной экономики, отрасль с огромным экспортным потенциалом, которая должна и может стать символом национального успеха, технологического лидерства России - как это сделал, например, наш оборонно-промышленный комплекс ${ }^{1}$.

В силу вышеизложенного, руководителям всех уровней управления надо понимать и осознавать, что основным вектором их инновационного мышления является совершенствование и обновление материально-технологической базы производства, создание методов по сокращению затрат на всех этапах инновационно-производственного цикла при разработке и создании новшеств с последующей их реализацией, то есть получение инновационного товара и нового уровня развития (рис. 2).

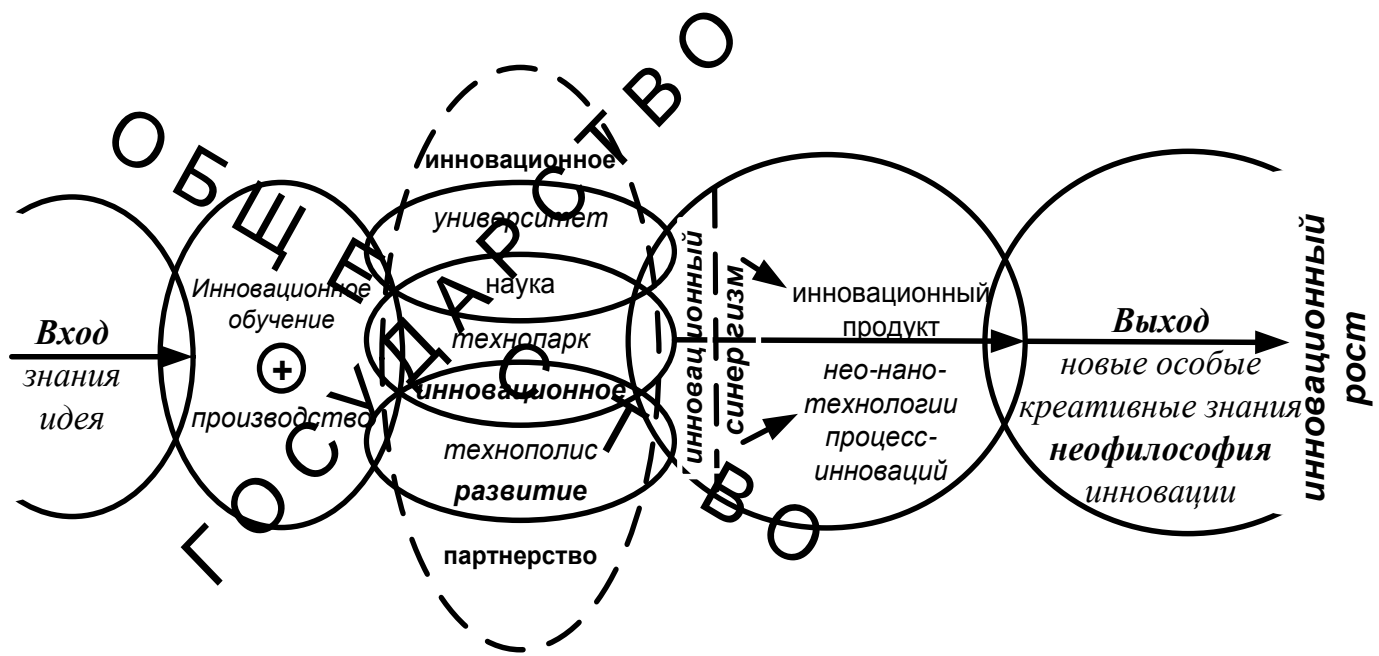

Рис. 2. Инновационный цикл НЕОобновления

Авторы отмечают, что анализ производительности труда показывает необходимость научного прогнозирования создания технологических возможностей не только обновления производства во всех отраслях экономики, но и воссоздание инновационного уровня производственной науки во всех приоритетных отраслях промышленности, на примере 000 «КЗ"Ростсельмаш"», создавшего интеллектуальную модель комбайна, убирающего хлеб без комбайнера, более того, без импорта в его деятельности. Президент РФ В.В. Путин управлял этим комбайном, посетив в феврале 2018 г. эту компанию.

В Краснодаре на совещании по АПК привел он 000 «КЗ"Ростсельмаш"», как пример инновационного развития: «У России есть трудолюбивые и образованные люди - люди, имеющие стремление быть всегда первыми; в национальном характере наших людей - привычка побеждать, стремление быть свободными и независимыми»2.

Как показывает практика инновационного развития лидеров-новаторов организации, лидером становится тот, кто действует, идет вперед, готов и способен реализовать инновационные преобразования в своей деятельности, достигая мирового уровня производительности труда, осуществляя ее на основе принципа научной организации труда и творческого патриотизма персонала, а также создавая инновационно-гуманные ценности для людей, определяющие нравственную справедливость в коллективе - это и есть степень инновационного развития экономики [2].

В соответствии с вышеизложенным, становится очевидным, что реализация справедливости в кризисных условиях будет определяться:

- умением руководителей-организаторов предвидеть будущую ситуацию развития;

- способностью создать и применить инновационные знания персонала;

- созданием и реализацией собственных инновационных технологий на производстве;

- высоким социально-экологическим инновационным уровнем инновационного климата;

- гибкой и прозрачной системой инномотивации каждого участника процесса;

\footnotetext{
1 Путин В.В. Выступление на съезде Союза машиностроителей России 19.04.2016 г.

2 Путин В.В. «О стратегии развития России до 2020 года. Выступление на расширенном заседании Госсовета» 8 февраля 2008 г. http://www.kremlin.ru/events/president/transcripts/24825
} 
- научной диффузией инновационных технологий в производстве;

- доверительным партнерством руководителей с персоналом.

Пример. Компания ООО «КЗ "Ростсельмаш"» создала «Академию образования» не только для подготовки собственных кадров, но и производит инновационное обучение как профессоров институтов и университетов России, так и комбайнеров всех регионов РФ, воплощая призыв Президента РФ В.В. Путина - «нам нужно всем вместе осуществить инновационный рывок-форсайт, тогда мы победим».

Анализ вышеизложенного показывает, что изменения инновационно-информационноцифровых технологий обуславливают возрастающую роль:

- знаний человека как источника и их создателя;

- личностных качеств - восприимчивости к новшествам;

- гибкого регулирования социальных процессов;

- научного управления производством с его обновлением;

- формирования инновационного климата в коллективе.

С научной точки зрения, создание и функционирование инновационного образования предопределяет аспект социализации личности, так как мгновенно изменяющиеся инновационноинформационные технологии способствуют быстрой самореализации личности и заставляют ее заниматься постоянным самосовершенствованием, то есть приоритет принадлежит ее ценностям внутренним убеждениям, которые изменяют поведение, что способствует социальному равновесию и становлению новой философии инновационного образования с вектором новационносоциального партнерства в коллективе - формирование неосоциальной психологии человека - духовное единство личности и неообщества.

Чарльз Грегг в своей работе «Мудрость нельзя передать словами» отмечает, что в жизни человек по своей эволюции природы должен уметь быть руководителем-организатором, то есть иметь способность создать гармонию целого в своей деятельности с учетом личной нравственной ответственности в сфере человеческих отношений, имея уровень интеллектуальной компетентности, что предопределит партнерские доверительные дружеские взаимоотношения с людьми и создание творческой атмосферы в коллективе.

Авторы считают, что только инновационное мышление руководителей-организаторов и интеллект персонала являются ключевым вектором гибкой инновационной деятельности организации, обладающие способностью генерировать новые особые знания в синергию инновационного творчества всего коллектива для достижения инновационной цели - становление новой модели экономики - инновационной.

В кризисной экономике приходит осознание того, что инновационное ее развитие обуславливается творчеством и инновационными знаниями человека, самореализация которого предопределяет создание новых инновационных знаний и новых ценностей организации, то есть человек - это созидатель и источник постоянного обновления общества.

Исходя из вышеизложенного, лидеры в инновационном развитии обновляют свои ключевые ценности, компетенции и знания персонала на основе инновационной философии, определяющие инновационную стратегию и тактику с учетом инновационных изменений психологии человека, осуществляя не только жизненный цикл организации, но и временной аспект инновационных совершенствований на всех уровнях управления и во всех подразделениях в своем инновационном развитии.

Так, Ю.В. Яковец в своих исследованиях отмечает, что «в основе инновационной динамики общества лежит новое развитие человека, его духовного мира - неонауки, инновационной культуры, иннообразования, материализующихся в средствах труда, преобразованных разумом и трудом людей» [7].

Логика вышеизложенного находит отражение в Докладе Римскому клубу (1979 г.) «Нет пределов обучению» с определением термина «инновационное обучение» - процесс, определяющий инновационные изменения в знаниях, культуре и социальной среде, реакция на проблемные ситуации, возникающие в жизни человека и общества в эпоху инноватики», то есть готовность принять на себя ответственность за результаты деятельности, определяющие истинные ценности в жизни людей, так как становление инновационного сознания профессионалов-новаторов предопределяет креативный подход для создания социально-экологической среды развития общества.

Анализ идеологии лидеров-компаний показывает, что все методы и приемы гуманного воздействия на сотрудников - это инструменты, способствующие выполнению всех функций при достижении инновационных целей, которые характеризуются универсальностью и специфичностью с учетом восприимчивости сотрудников к изменениям. 
Пример. Очень важно в условиях кризиса научное осмысление значимости собственной производственной науки руководителями организации, которая не только обеспечивает инновационное конкурентное развитие, но и определяет постоянное создание новых особых знаний у персонала, что и осуществляют руководители 000 «КЗ "Ростсельмаш"» сейчас с пониманием того, что интеллект человека - это индивидуальная его компетентность, включающая не только новые знания, но и умения, навыки, образование, новаторский порыв, честность, инсайт, ответственность, гуманную культуру и создаваемые им ценности [2].

Так, компания 000 «КЗ "Ростсельмаш"» разрабатывает собственные инновационные программы по разработке и созданию инновационного ряда комбайнов, реализуемые моделями инновационной деятельности, что определяет гибкое освоение различных аспектов поведения в коллективе с ориентацией на инновазию с инновационным мышлением ее руководителей, что позволяет осуществить генерацию новых идей с их реализацией инновационными принципами организации производства - самосовершенствование.

С теоретической точки зрения, креативное мышление персонала - результат процесса творческой деятельности руководителей с социально-экологической направленностью. Согласно логике циклического развития общества инновационное мышление - высокая степень креативности на новых особых знаниях, то есть вектор гуманно-морально-нравственно-духовного самосовершенствования и самореализации личности.

В современных условиях становление новой экономики характеризуется тенденцией к социализации, то есть превращение экономического роста в инновационный тип развития экономики, где мораль превращается в нравственную потребность с гуманным экономическим поведением участников творческого процесса [2].

В подтверждение этому П. Друкер в своих исследованиях отмечал, что новшество, внедренное в производство, переходит в инновационный результат инновационной деятельностью, которая не только обладает экономической целесообразностью и ценой, но и имеет общественную ценность в виде социальной инновации - это изменение нового типа мышления и стиля жизни каждой личности.

Практика лидеров-компаний по созданию новых особых знаний показывает, что истинная ценность затраченного времени и инвестиций определяется эффективностью использования этих знаний при реализации инновационных проектов.

Пример: компания 000 «КЗ "Ростсельмаш"» создает новые особые знания персонала путем гуманных методов:

- стимулирование каждого работника не только за идею, но и ее практическую реализацию через систему «Пуск»;

- создание инновационного центра обучения всех работников;

- формирование инновационной культуры во всех подразделениях;

- гибкий социальный пакет.

Однако эти примеры показывают, что при создании и реализации универсальной модели организационного знания руководителям организации следует объединить преимущества как западного, так и японского подходов, поскольку создание новых знаний - основа реализации инновационного управления в условиях НЕОинформационного общества и глобальной кризисной экономики.

На практике топ-менеджеры должны понимать, что мы живем и трудимся в неоинформационном обществе, где все, взаимодействуя, создают ценнейший ресурс экономики - новые особые знания работников, что определяет его инновационное развитие.

По определению Б. Мартина, форсайт представляет процесс, связанный с систематической попыткой заглянуть в отдаленное будущее науки, инновационные технологии в экономике и обществе с целью определения областей стратегических исследований и технологий, которые, вероятно, могут принести наибольшие экономические и социальные выгоды [8].

С научной точки зрения, только инновационно-социально-гуманные технологии предопределяют сущность духовного развития человечества в контексте инновационного возрождения нравственности, этики и социальной справедливости, так как человек - созидатель, предопределяющий инновационное развитие общества своим интеллектом и пониманием необходимости выживания только для создания духовности и мира всем людям.

\section{Литература}

1. Овчаренко Г.В., Ларкина Н.Г., Овакимян М.А., Мелихова Б.С. Инновазия социально-технологических систем в новой экономике. Монография. Ростов н/Д.: Изд-во ЮРИУ РАНХиГС, 2019.126 с.

2. Овчаренко Г.В., Ларкина Н.Г. Инновационное управление. Учебник. Ростов н/Д.: Изд-во ЮРИУ РАНХиГС. 333 с. 
3. Путин В.В. Нам нужна новая экономика // Ведомости. №3029 от 30.01.2012.

https://www.vedomosti.ru/politics/articles/2012/01/30/o_nashih_ekonomicheskih_zadachah

4. Вернадский В.И. Философские мысли натуралиста. М.: Наука, 1988. 520 с.

5. Валентей С.Д. На пути к мировой цивилизации // Вопросы экономики. 1993. № 11. С. 53 - 61.

6. Овчаренко Г.В., Ларкина Н.Г. Инновационное управление. Практикум: учебное пособие. Ростов н/Д.: Изд-во ЮРИУ РАНХиГС, 2018. 303 с.

7. Яковец Ю.В. Инновации: теория, механизм, государственное регулирование. Учебное пособие. М.: РАГС, 2002. 237 c.

8. Ben R. Martin. Technology Foresight in a Rapidly Globalizing Economy - SPRU - Science and technology Policy research University of Science, 1995.

9. Шепель В.М. Человековедческая компетентность менеджера. Управленческая антропология. - М.: Дом педагогики, 2000. 543 c.

Ovcharenko Georgy Vasilyevich, Doctor of Economic Science, Professor of Cathedra of Management, SouthRussia Institute of Management - branch of Russian Presidential Academy of National Economy and Public Administration. (70/54, Pushkinskaya St., Rostov-on-Don, 344002, Russian Federation).

E-mail: menedjment@uriu.ranepa.ru

Larkina Nataliya Georgievna, Candidate of Economic Science, Docent of Cathedra "Marketing and Communications in Business", Southern Federal University (105/42, Bolshaya Sadovaya St., Rostov-on-Don, 344006, Russian Federation). E-mail: nat1-la@yandex.ru

Nekrasova Victoria Vitalievna, Candidate of economic Sciences, head of the Department of management, associate Professor, South-Russia Institute of Management - branch of Russian Presidential Academy of National Economy and Public Administration (70/54, Pushkinskaya St., Rostov-on-Don, 344002, Russian Federation).

E-mail: menedjment@uriu.ranepa.ru

\section{INNOVATIVE TRANSFORMATIONS AS AN IMPERATIVE OF INDUSTRIAL POLICY IMPLEMENTATION}

Abstract

The article deals with the moral and ethical aspects of innovation transformations in the innovation activity of organizations. The necessity of innovative activity of the person in his life activity is grounded on practical situations. The importance of innovative culture in creating social balance in the team is shown. The models of strategicinnovative diversification of innovative development of society are offered. Possibilities of reproduction of innovative potential taking into account personal responsibility of heads are defined. The assessment of key factors of innovative transformations in the context of innovative education and innovative thinking of managers is given. The features of innovative knowledge management are outlined.

Keywords: moral and ethical aspects, innovative climate, self-improvement of personality, innovative development, innovative activity, innovative knowledge, innovative potential, renewal of production, innovative values.

\section{References}

1. Ovcharenko G.V., Larkina N.G.,Ovakimyan M.A., Melihova B.S. Innovaziya social'no-tekhnologicheskih sistem v novoj ekonomike. Monografiya. Rostov n/D.: Izd-vo YURIU RANHiGS, 2019. 126 p.

2. Ovcharenko G.V., Larkina N.G. Innovacionnoe upravlenie. Uchebnik. Rostov n/D.: Izd-vo YURIU RANHiGS. $333 \mathrm{p}$.

3. Putin V. Nam nuzhna novaya ekonomika // Vedomosti. №3029 ot 30.01.2012. https://www.vedomosti.ru/politics/articles/2012/01/30/o_nashih_ekonomicheskih_zadachah

4. Vernadskij V.I. Filosofskie mysli naturalista. M.: Nauka, 1988. 520 p.

5. Valentej S.D. Na puti k mirovoj civilizacii // Voprosy ekonomiki. 1993. № 11. P. 53 - 61.

6. Ovcharenko G.V., Larkina N.G. Innovacionnoe upravlenie. Praktikum: uchebnoe posobie. Rostov n/D.: Izd-vo YURIU RANHiGS, 2018. 303 p.

7. YAkovec YU.V. Innovacii: teoriya, mekhanizm, gosudarstvennoe regulirovanie. Uchebnoe posobie. - M.: RAGS, 2002. $237 \mathrm{ps}$.

8. Ben R. Martin. Technology Foresight in a Rapidly Globalizing Economy - SPRU - Science and technology Policy research University of Science, 1995.

9. SHepel' V.M. CHelovekovedcheskaya kompetentnost' menedzhera. Upravlencheskaya antropologiya. - M.: Dom pedagogiki, $2000.543 \mathrm{p}$. 